\title{
Corneal Densitometry in Different Grades of Myopia
}

\section{Dina M. AbdelAzim, Rania K. Farag, Hossam T. El Sharkawy, Amgad M. El Nokrashy.}

Mansoura Ophthalmic Center, Faculty of Medicine, Mansoura University, Egypt

Corresponding author: Dr. Dina M. AbdelAzim, Mansoura Ophthalmic Center, Faculty of Medicine, Mansoura University, Egypt. Tel: 01067388858; Email: drteto1982@gmail.com.

Received: 11-9-2021, Accepted: 1-10-2021, Published online:16-12-2021

EJO(MOC) 2021;4:206-213.

Running title: Corneal densitometry of myopia.

\section{Abstract}

Purpose: Myopia is a common pathologic change in the eye and almost unavoidable. Myopic changes in the eyes include extended axial length, deeper anterior chamber, a thinner retina and a higher retinal detachment prevalence, lower choroid circulation. Corneal densitometry reflects corneal clarity as well as health. The internal structure of the cornea reduces the scattering of light to a minimum. Increased corneal light dispersal in different corneal disorders has been reported.

Objective: Evaluate corneal densitometry values obtained using Scheimpflug tomography in different grades of myopic eyes for patients attending to Mansoura University Ophthalmic Center.

Patients and methods: This cross-sectional study included 45 Myopic patients who were recruited over one year from November 2019 to October 2020. Patients were classified into three grades; low myopia, moderate myopia and high myopia. All cases had history and complete ophthalmic examination including visual acuity assessment, autorefractometer testing and slit lamp examination. The Pentacam Scheimpflug imaging system was used to examine myopic cornea.

Results: There was a statistically significant difference in the corneal densitometry in the (6-10 $\mathrm{mm})$ zone in all in the total, anterior, central and posterior corneal layers. There was no statistically significant difference between the different grades of myopia regarding the corneal densitometry of the other different zones of the corneal regions.

Conclusion: Assessment of corneal densitometry by pentacam could be used as a method of assessment of corneal clarity between different cases with myopia.

Key words: Myopia, Corneal densitometry, Pentacam, Scheimpflug tomography.

\section{Introduction:}

Myopia is one of the most common eye conditions worldwide with an estimated impact of 1,5 billion person. A huge increase in the prevalence of myopia has been reported ${ }^{1}$.

There is still a debate on modifications in corneal parameters of myopic eyes, such as corneal curvature, corneal thickness and density 2, 3. Earlier investigations into the biomechanical properties of cornea have shown that hysteresis in the cornea is significantly less in myopia and that some aspects of corneal biomechanical characteristics, such as elasticity, viscosity, hydration, rigidity, can affect myopic eyes ${ }^{4}$.

Corneal densitometry (CD) is a noninvasive and quantitative measurement that provides information about the transparency of the cornea ${ }^{5}$.

Scheimpflug photography is a relatively new method for quantifying light scattering and helping in the evaluation of corneal clarity ${ }^{6}$ For corneal topography, Pentacam HR, a nonInvasive, rapid and multifunctional optical system, may be used 
to evaluate the anterior segment from a prior corneal surface up to the posterior lens surface ${ }^{7}$.

In this study we aimed to evaluate corneal densitometry values in different grades of myopic eyes

\section{Patients and methods}

This is a cross sectional study that was conducted at Mansoura ophthalmic center, Mansoura University, Mansoura, Egypt. Along the period of one year from November 2019 to October 2020.

This study included total number of 45 Myopic with cycloplegic myopic refraction. Patients were classified into three grades; low myopia (of -3.00 diopters or less), moderate myopia between -3.00 and -6.00 diopters) and high myopia (with refractive error more than -6.00 diopters).

The cases with the following conditions were excluded; corneal opacity as nebula, previous corneal surgery as LASIK, patients diagnosed with glaucoma, patients with anterior or posterior uveitis, Pseudo myopia and patients with other anterior segment pathology.

After approval from the institutional review board (IRB) NO:MS.19.12.959 of Mansoura Faculty of Medicine and obtaining an informed written consent from the participants, all cases were subjected to complete history taking and through Fully detailed ophthalmic examination was done for all the cases including assessment of the visual acuity (VA) using Landolt's VA chart and then transformed for statistical analysis to logarithm of minimal angle of resolution units (Log MAR).

Autorefractometry (autorefractor keratometer-HUVITZ, China) was used to provide an objective measurement of a person's refractive error (With and without cycloplegia)

Slit lamp biomicroscopy (20 SL- Slit Lamp - ZEISS, Germany) was used to assess corneal clarity, anterior chamber for depth and regularity, pupil shape, size, regularity and reactivity and state of the lens. The fundus was examined in each case by using slit lamp with +90 Volk lens (After installation of mydriatic eye drops).

Myopic corneas were examined using the Pentacam Scheimpflug imaging system. Corneal densitometry was automatically performed over a $12-\mathrm{mm}$ zones $(0-2 \mathrm{~mm}, 2-$ $6 \mathrm{~mm}, 6-10 \mathrm{~mm}, 10-12 \mathrm{~mm}$, total diameter) also corneal depth (anterior layer: inner120 $\mu \mathrm{m}$; center layer: from $120 \mu$ $\mathrm{m}$ to the last $60 \mu \mathrm{m}$; posterior layer: last $60 \mu \mathrm{m}$; total corneal thickness.

\section{Statistical analysis}

Data analysis was performed by Statistical Package for the Social Sciences (SPSS 26.0, IBM/SPSS Inc., Chicago, IL) software. Categorical data were expressed as frequencies and percentages (\%) while in the quantitative data, we used mean and standard deviations (SD) as well as median (range).

To compare three groups with categorical variables, ChiSquare test (or Fisher's exact test) were used. To compare three groups with normally distributed quantitative variables, one way analysis of the variance test (one-way ANOVA) was used. Probability ( $\mathrm{p}$ value) $\leq 0.05$ was considered to be statistically significant.

\section{Results}

As shown in table (1), the mean age of the cases is $31.33 \pm 6.51$ years with range between 20 and 50 years. There were 9 males $(20 \%)$ and 36 females $(80.0 \%)$.

The mean UCVA was $0.98 \pm 0.26 \log \mathrm{MR}$ with range between 0.5 and $1.8 \log$ MR. The mean BCVA was $0.21 \pm$ $0.25 \log \mathrm{MR}$ with range between 0 and $0.8 \log \mathrm{MR}$. The mean spherical axis was $-5.44 \pm 4.25 \mathrm{D}$ with range between $-1.25 \mathrm{D}$ and $-15.25 \mathrm{D}$. The mean cylinder axis was $-0.72 \pm 0.44 \mathrm{D}$ with range between -2 and $0 \mathrm{D}$. 
Table (1): Demographic and basic clinical data in the study cases

\begin{tabular}{|c|c|c|c|}
\hline & \multicolumn{3}{|c|}{ Total number $=45$} \\
\hline & mean \pm SD & Median & Range \\
\hline Age/years & $31.33 \pm 6.51$ & ----- & $(20-50)$ \\
\hline Males & & $9(20 \%)$ & \\
\hline Females & & $36(80 \%)$ & \\
\hline UCVA (Log Mar) & $0.98 \pm 0.26$ & 1.0 & $(0.5-1.8)$ \\
\hline BCVA (Log Mar) & $0.21 \pm 0.25$ & 0.2 & $(0-0.8)$ \\
\hline Spherical (Diopter) & $-5.44 \pm 4.25$ & -3.7 & $(-15.25--1.25)$ \\
\hline Cylinder (Diopter) & $-0.72 \pm 0.44$ & -1.0 & $(-2.0-0)$ \\
\hline
\end{tabular}

The different corneal densitometry values of the different corneal layers are shown in table (2),

Table (2): Corneal densitometry of the different corneal layers in the study cases

\begin{tabular}{|c|c|c|c|}
\hline & \multicolumn{3}{|c|}{ Total number $=45$} \\
\hline & mean $\pm \mathrm{SD}$ & Median & Range \\
\hline \multicolumn{4}{|c|}{ Anterior layer } \\
\hline From 0-2 & $21.16 \pm 4.71$ & 20.50 & $12.70-38.10$ \\
\hline From 2-6 & $19.14 \pm 3.93$ & 18.40 & $13.90-32.90$ \\
\hline From 6-10 & $19.69 \pm 4.35$ & 19.60 & $12.10-27.50$ \\
\hline From 10-12 & $26.26 \pm 8.43$ & 27.10 & $9.6-50.9$ \\
\hline Total & $21.00 \pm 3.68$ & 20.80 & $12.60-29.50$ \\
\hline \multicolumn{4}{|l|}{ Central layer } \\
\hline From 0-2 & $12.73 \pm 1.31$ & 12.80 & $9.30-16.30$ \\
\hline From 2-6 & $11.67 \pm 1.07$ & 11.70 & $9.30-14.30$ \\
\hline From 6-10 & $13.01 \pm 2.31$ & 12.70 & $8.50-18.20$ \\
\hline From 10-12 & $17.04 \pm 4.10$ & 16.90 & $7.30-27.90$ \\
\hline Total & $13.44 \pm 2.19$ & 13.70 & $8.90-24.10$ \\
\hline \multicolumn{4}{|c|}{ Posterior layer } \\
\hline From 0-2 & $10.46 \pm 2.21$ & 10.20 & $8.00-19.60$ \\
\hline From 2-6 & $9.36 \pm 0.83$ & 9.40 & $7.60-10.90$ \\
\hline From 6-10 & $10.82 \pm 1.59$ & 11.00 & $8.10-14.70$ \\
\hline From 10-12 & $13.15 \pm 3.02$ & 12.80 & $6.90-20.90$ \\
\hline Total & $10.61 \pm 1.13$ & 10.60 & $8.10-13.80$ \\
\hline \multicolumn{4}{|l|}{ Total layer } \\
\hline From 0-2 & $14.65 \pm 2.21$ & 14.50 & $10.10-22.10$ \\
\hline From 2-6 & $13.39 \pm 1.84$ & 13.30 & $10.30-19.30$ \\
\hline From 6-10 & $14.50 \pm 2.63$ & 14.60 & $9.60-19.00$ \\
\hline From 10-12 & $18.81 \pm 4.95$ & 18.70 & $7.90-33.20$ \\
\hline Total & $14.94 \pm 1.95$ & 15.40 & $9.90-18.60$ \\
\hline
\end{tabular}


The cases were classified into 3 groups according to the degree of myopia, each group consists of 15 cases; mild, moderate and high myopia. There was no statistically significant difference between the cases of the different grades of myopia regarding the mean age and sex distribution. Females represent the higher percentage of the cases in the three groups.

Table (3): Association between grade of myopia and demographic data

\begin{tabular}{|c|c|c|c|c|}
\hline \multicolumn{5}{|c|}{ Study group } \\
\hline Variables & $\begin{array}{c}\text { Mild Myopia } \\
\qquad(\mathrm{N}=15)\end{array}$ & $\begin{array}{c}\text { Moderate } \\
\text { Myopia } \\
(\mathrm{N}=15)\end{array}$ & $\begin{array}{l}\text { High Myopia } \\
\qquad(\mathrm{N}=15)\end{array}$ & Test of significance \\
\hline \multicolumn{5}{|c|}{ Age } \\
\hline \multirow{4}{*}{ Mean \pm SD } & & & & $P=0.78$ \\
\hline & $30.40 \pm$ & $32.07 \pm$ & $31.53 \pm$ & $P 1=0.56$ \\
\hline & 7.15 & 8.21 & 3.64 & $\mathrm{P} 2=0.59$ \\
\hline & & & & $\mathbf{P 3}=\mathbf{0 . 8 2}$ \\
\hline \multicolumn{5}{|c|}{ Sex } \\
\hline \multirow[t]{2}{*}{ Males } & $2(13.3 \%)$ & $3(20 \%)$ & $4(26.7 \%)$ & $\mathbf{P}=\mathbf{0 . 8 9}$ \\
\hline & & & & $\mathbf{P 1}=1$ \\
\hline \multirow[t]{2}{*}{ Females } & $13(86.7 \%)$ & $12(80 \%)$ & $11(73.3 \%)$ & $\mathrm{P} 2=0.65$ \\
\hline & & & & $\mathbf{P 3}=\mathbf{1}$ \\
\hline \multicolumn{5}{|c|}{ * statistically significant if $\mathrm{P} \leq 0.05$} \\
\hline \multicolumn{5}{|c|}{ P1: comparison between mild and moderate myopia } \\
\hline \multicolumn{5}{|c|}{ P2: comparison between mild and high myopia } \\
\hline \multicolumn{5}{|c|}{ P3: comparison between moderate and high myopia } \\
\hline
\end{tabular}

The mean densitometry score of the $0-2$ zone of the anterior corneal layer was statistically significantly lower in the cases with mild myopia as compared with the cases with moderate myopia. The mean densitometry score of the 2-6 zone of the anterior corneal layer was statistically significantly lower in the cases with mild myopia as compared with the cases with moderate myopia.

The mean densitometry score of the 6-10 zone of the anterior corneal layer was statistically significantly lower in the cases with severe myopia as compared with the cases with moderate myopia.

Other parameters didn't show a statistically significant difference between the different grades of myopia.
The mean densitometry score of the 6-10 zone of the posterior corneal layer was statistically significantly lower in the cases with severe myopia as compared with the cases with moderate myopia. Other parameters didn't show a statistically significant difference between the different grades of myopia.

The mean densitometry score of the 2-6 zone of the total corneal layer was statistically significantly lower in the cases with mild myopia as compared with the cases with moderate myopia. The mean densitometry score of the 6-10 zone of the total corneal layer was statistically significantly lower in the cases with mild myopia and cases severe myopia as compared with the cases with moderate myopia. Other parameters didn't show a statistically significant difference between the different grades of myopia. 
Table (4): Association between grade of myopia and corneal densitometry of different corneal layers

\begin{tabular}{|c|c|c|c|c|}
\hline Variables & $\begin{array}{c}\text { Mild Myopia } \\
(\mathbf{N}=15)\end{array}$ & $\begin{array}{c}\text { Study group } \\
\text { Moderate Myopia } \\
(\mathbf{N}=15)\end{array}$ & $\underset{(\mathbf{N}=15)}{\text { High Myopia }}$ & Test of significance \\
\hline \multicolumn{4}{|l|}{ Anterior layer } & \multirow{5}{*}{ 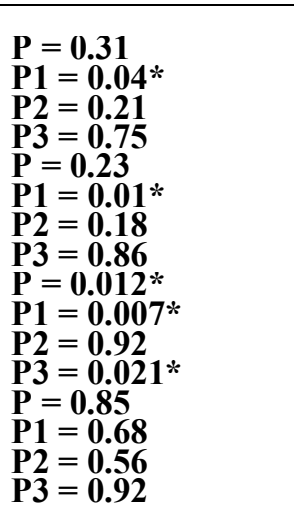 } \\
\hline From $0-2$ & $19.66 \pm 2.11$ & $21.58 \pm 2.73$ & $22.23 \pm 7.35$ & \\
\hline From 2-6 & $17.72 \pm 1.79$ & $19.70 \pm 2.08$ & $19.99 \pm 6.14$ & \\
\hline From 6-10 & $18.30 \pm 3.09$ & $22.34 \pm 4.37$ & $18.43 \pm 4.429$ & \\
\hline From 10-12 & $27.25 \pm 7.37$ & $25.93 \pm 10.24$ & $25.60 \pm 7.91$ & \\
\hline \multicolumn{4}{|l|}{ Central layer } & \multirow{6}{*}{$\begin{array}{l}P=0.86 \\
P 1=0.95 \\
P 2=0.65 \\
P 3=0.68 \\
P=0.47 \\
P 1=0.15 \\
P 2=0.79 \\
P 3=0.43 \\
P=0.023 \\
P 1=0.08 \\
P 2=0.34 \\
P 3=0.004 \\
P=0.45 \\
P 1=0.46 \\
P 2=0.19 \\
P 3=0.64 \\
P=0.25 \\
P 1=0.84 \\
P 2=0.20 \\
P 3=0.043 *\end{array}$} \\
\hline From 0-2 & $12.64 \pm 1.03$ & $12.67 \pm 1.03$ & $12.88 \pm 1.80$ & \\
\hline From 2-6 & $11.48 \pm 0.75$ & $11.94 \pm 0.94$ & $11.58 \pm 1.41$ & \\
\hline From 6-10 & $12.81 \pm 2.51$ & $14.23 \pm 1.74$ & $11.98 \pm 2.17$ & \\
\hline From 10-12 & $18.06 \pm 4.16$ & $16.88 \pm 4.59$ & $16.17 \pm 3.54$ & \\
\hline Total & $13.91 \pm 3.20$ & $13.75 \pm 0.94$ & $12.67 \pm 1.71$ & \\
\hline \multicolumn{4}{|l|}{ Posterior layer } & \multirow{5}{*}{$\begin{array}{l}P=0.045 * \\
P 1=0.89 \\
P 2=0.07 \\
P 3=0.06 \\
P=0.45 \\
P 1=0.25 \\
P 2=0.31 \\
P 3=0.95 \\
P=0.033 \\
P 1=0.14 \\
P 2=0.29 \\
P 3=0.004 \\
P=0.32 \\
P 1=0.54 \\
P 2=0.12 \\
P 3=0.38\end{array}$} \\
\hline From $0-2$ & $9.91 \pm 1.01$ & $9.87 \pm 0.85$ & $11.61 \pm 3.39$ & \\
\hline From 2-6 & $9.14 \pm 0.85$ & $9.48 \pm 0.77$ & $9.47 \pm 0.89$ & \\
\hline From 6-10 & $10.77 \pm 1.83$ & $11.59 \pm 1.02$ & $10.11 \pm 1.54$ & \\
\hline From $10-12$ & $13.94 \pm 2.94$ & $13.25 \pm 3.23$ & $\begin{array}{c}12.26 \pm \\
2.82\end{array}$ & \\
\hline From $0-2$ & $14.08 \pm 1.34$ & $14.72 \pm 1.40$ & $15.14 \pm 3.30$ & \multirow{4}{*}{ 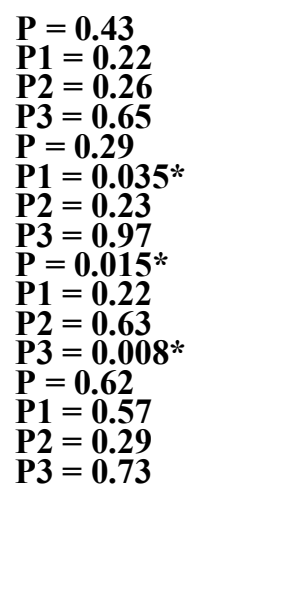 } \\
\hline From 2-6 & $12.78 \pm 1.07$ & $13.72 \pm 1.24$ & $13.69 \pm 2.71$ & \\
\hline From 10-12 & $19.76 \pm 4.43$ & $18.67 \pm 5.88$ & $17.99 \pm 4.60$ & \\
\hline \multicolumn{4}{|c|}{$\begin{array}{l}\text { * statistically significant if } \mathrm{P} \leq 0.05 \\
\text { P1: comparison between mild and moderate myopia } \\
\text { P2: comparison between mild and high myopia } \\
\text { P3: comparison between moderate and high myopia }\end{array}$} & \\
\hline
\end{tabular}




\section{Discussion:}

Scheimpflug systems illuminate the cornea perpendiculary and analyze the corneal cross section from an angle of $\pm 45^{\circ}$. Corneal stroma provides a normal layout of collagen fibrils, homogenous fibroids and a uniform diameter for corneal transparency ${ }^{\mathbf{1 5}}$.

This study was conducted to evaluate corneal densitometry values obtained using Scheimpflug tomography in different grades of myopic eyes for patients attending to Mansoura university Ophthalmic Center.

To the best of our knowledge, this is the first study to compare the different grades of myopia regarding the corneal densitometry.

The current study included 45 myopic patients. The mean age of the cases is $31.33 \pm 6.51$ years with range between 20 and 50 years. There were 9 males (20\%) and 36 females $(80.0 \%)$.

There was no statistically significant difference between the cases of the different grades of myopia (mild, moderate and high myopia) regarding the mean age and sex distribution. Females represent the higher percentage of the cases in the three groups.

This came in accordance with Wang et al. (2016) who reported that there were no significant differences in age, gender between the group of patients (mild myopia, moderate myopia and high myopia) included in their study ${ }^{8}$

Similar results were reported Fan et al. (2017) where there was no significant difference in age among the three groups (mild myopia, moderate myopia and high myopia) included in their study ${ }^{9}$

In the study conducted by Guo et al. (2019), a total of 174 eyes from 174 healthy Korean subjects were included. The eyes were divided into four groups according to refraction: emmetropia, mild myopia, moderate myopia and high myopia. They reported insignificant differences between the four groups in the age and sex distribution $(p>$ 0.05 ) among the four groups ${ }^{10}$.
In the current study, there was a statistically significant difference in the corneal densitometry in the $(6-10 \mathrm{~mm})$ zone in all in the anterior, central and posterior corneal layers. In the anterior layer, the cases with mild myopia had the lowest densitometry values while in all the other layers, the cases with high myopia had the lowest values.

Dong and his colleagues divided the cornea into three layers. On densitometry of the central and back elevations, all concentrated ring areas were found to have less light backscatter within the high myopia group than in the normal group. The anterior density values in the $10-12 \mathrm{~mm}$ ring zone in the high myopia group were however higher than in the normal group (high myopia $=46.4 \pm 14.2$, normal $=$ $41.1 \pm 13.5, P=0.004)^{11}$.

In case of high myopia less values may be explained as a result of a corneal biomechanical property change in high myopia, changes in the cellular density of corneal endothelia in low and moderate myopic eyes and possible changes in corneal structures, such as nerves, cell nuclei, corneal fibrils, collagen fibril size, and extracellular matrix around collagen fibril and corneal hydration ${ }^{4,12,13}$.

In the current study, there was no statistically significant difference in the peripheral $(10-12 \mathrm{~mm})$ zone in the total, anterior, central and posterior corneal layers.

Dong and his colleagues agreed that no significant difference between the two groups or higher levels of corneal densitometry were found in the high myopia group (diameter 10 to $12 \mathrm{~mm}$ ) than in the control group were found in the periphery ${ }^{11}$.

Nalcaciogluet al. reported that the myopic cases were not different to those of hyperopia but had lower central and post-6-10 $\mathrm{mm}$ pericentral corneal density values in comparison with emmetropic cases ${ }^{14}$

This results should be interpreted with caution in clinical practice because of the low reproducibility and reproductivity of the peripheral densitometry measures reported in a prior normative $\operatorname{study}^{\mathbf{1 5}}$. In the automatic corneal densitometry analysis, the variation in white-towhite distance that could lead the inclusion of some 
proportion of limbus and sclera could erroneously lead to higher corneal densitometry values ${ }^{\mathbf{1 6}}$.

In the various layers of the cornea the various results of the posterior stroma are more transparent on the cornea than the previous stroma with a structural pattern ${ }^{13},{ }^{17}$.The keratocyte density is also higher in the front cornea than in the central and back cornea ${ }^{\mathbf{1 8}}$.

The process of emmetropisation seems normally dependent on the visual input and the absence of normal input could cause refractive errors ${ }^{19-21}$.

This made us realize that corneal optical density values can help to develop refractive errors because visual data are not clear. Different optical factors in the eyes with diverse refractive errors can equalize the presence of corneal densitometry values in different areas in myopic and hyperopic cases different from emmetropic ${ }^{19}$.

Despite the results obtained in the current study, there are some limitations reported. First, the small sample size included and it is a single center study. Second, this study didn't include a control group and didn't enable comparison of the different results with the normal corneal densitometry values. Finally, we didn't assess the other corneal parameters as the corneal thickness and this could enable to establish the relation between the densitometry values with other corneal parameters.

\section{Conclusion:}

The current findings suggested that assessment of corneal densitometry by pentacam could be a helpful method to differentiate between the different grades of myopia. Although there was no reported statistically significant difference between the different grades of myopia regarding the corneal densitometry of the other different zones of the corneal regions except the zone (6-10 $\mathrm{mm}$ ), but this could be due to the relatively small sample size.

\section{Recommendations:}

Based on the results of this study, it is recommended to perform further studies including larger number of patients from more than a single center. Also, it is recommended to perform further studies that include normal healthy control group to compare the corneal densitometry parameters as compared with the normal values.

\section{Conflict of Interest}

Authors declare no conflicts of interest

\section{Funding:}

This study is self-funding

\section{Conflict of Interest}

Authors declare no conflicts of interest.

\section{Corresponding author}

Correspondence to: Dina M. AbdelAzim

Email: drteto1982@gmail.com

\section{Affiliations}

Dina M. AbdelAzim, Mansoura Ophthalmic Center, Faculty of Medicine, Mansoura University, Egypt.

\section{Ethics declarations}

\section{Conflict of interest}

Dina M. AbdelAzim, Amgad M. El Nokrashy, Rania K.Farag, Hossam T. El Sharkawy, all authors have no conflicts of interest that are directly relevant to the content of this review.

Funding: No sources of funding were used to conduct this review.

Reviewer disclosures: No relevant financial or other relationships to disclose.

Declaration of interest: No financial affiliations or financial involvement with any organization or entity with a financial competing with the subject matter or materials discussed in the review.

\section{References}

1. Verhoeven VJ, Hysi PG, Wojciechowski R, Fan Q, Guggenheim JA, Höhn R, et al. Genome-wide metaanalyses of multiancestry cohorts identify multiple new susceptibility loci for refractive error and myopia. Nature genetics. 2013;45(3):314. 
2. Wang X, Dong J, Wu Q. Corneal thickness, epithelial thickness and axial length differences in normal and high myopia. BMC ophthalmology. 2015;15(1):1-5.

3. Fam H-B, How AC, Baskaran M, Lim K-L, Chan Y-H, Aung T. Central corneal thickness and its relationship to myopia in Chinese adults. British journal of ophthalmology. 2006;90(12):1451-3.

4. Shen M, Fan F, Xue A, Wang J, Zhou X, Lu F. Biomechanical properties of the cornea in high myopia. Vision research. 2008;48(21):2167-71.

5. Hüseyin K, YILMAZ U. Investigation of the relationship of corneal densitometry, corneal volume and central corneal thickness with age in healthy individuals. Journal of Surgery and Medicine. 2020;4(6):483-5.

6. Wegener A, Laser-Junga H. Photography of the anterior eye segment according to Scheimpflug's principle: options and limitations-a review. Clinical \& experimental ophthalmology. 2009;37(1):144-54.

7. Cho YK, Chang HS, La TY, Ji D, Kim H, Choi JA, et al. Anterior segment parameters using Pentacam and prediction of corneal endothelial cell loss after cataract surgery. Korean Journal of Ophthalmology. 2010;24(5):284-90.

8. Wang X, Kong X, Jiang C, Li M, Yu J, Sun X. Is the peripapillary retinal perfusion related to myopia in healthy eyes? A prospective comparative study. BMJ open. 2016;6(3):e010791.

9. Fan H, Chen H-Y, Ma H-J, Chang Z, Yin H-Q, Ng DS$\mathrm{C}$, et al. Reduced macular vascular density in myopic eyes. Chinese medical journal. 2017;130(4):445.

10. Guo Y, Sung MS, Park SW. Assessment of superficial retinal microvascular density in healthy myopia. International ophthalmology. 2019;39(8):1861-70.

11. Dong J, Zhang Y, Zhang H, Jia Z, Zhang S, Sun B, et al. Corneal densitometry in high myopia. BMC ophthalmology. 2018;18(1):1-6.
12. Delshad S, Chun JM. Corneal endothelial cell density and morphology in low and moderate myopic Chinese eyes. International journal of ophthalmology. 2013;6(4):467.

13. O’Donnell C, Wolffsohn JS. Grading of corneal transparency. Contact Lens and Anterior Eye. 2004;27(4):161-70.

14. Nalcacioglu P, Sen E, Aydemir E, Kiziltoprak H, Yasar HH. Objective Assessment of Corneal Backscattered Light in Myopic, Hyperopic, and Emmetropic Children. 2021.

15. Dhubhghaill SN, Rozema JJ, Jongenelen S, Hidalgo IR, Zakaria N, Tassignon M-J. Normative values for corneal densitometry analysis by Scheimpflug optical assessment. Investigative ophthalmology \& visual science. 2014;55(1):162-8.

16. Lopes B, Ramos I, Ambrósio Jr R. Corneal densitometry in keratoconus. Cornea. 2014;33(12):1282-6.

17. Spadea L, Maraone G, Verboschi F, Vingolo EM, Tognetto D. Effect of corneal light scatter on vision: a review of the literature. International journal of ophthalmology. 2016;9(3):459.

18. Ruberti JW, Sinha Roy A, Roberts CJ. Corneal biomechanics and biomaterials. Annual review of biomedical engineering. 2011;13:269-95.

19. Flitcroft D. Emmetropisation and the aetiology of refractive errors. Eye. 2014;28(2):169-79.

20. Neil Charman W, Radhakrishnan H. Peripheral refraction and the development of refractive error: a review. Ophthalmic and Physiological Optics. 2010;30(4):321-38.

21. Smith E, Hung L, Arumugam B. Visual regulation of refractive development: insights from animal studies. Eye. 2014;28(2):180-8. 